\title{
8. Lamarck on species and evolution
}

\author{
Marc F Oxenham
}

\section{Introduction}

For the last decade I have lived three doors down from Colin's office, in the bowels of the AD Hope building at The Australian National University. However, my first contact with Colin was indirect, in as much as he was an examiner of my Honours thesis ('Progress and Evolution: A re-evaluation of some ideas, devices and scholars in the study of human evolution to 1950') back in 1995 . Those familiar with the Australian and New Zealand university systems will realise that Honours is where undergraduates start to play with the big kids, and examiner's reports can be a rude entree to the world of academia. Colin's positive comments inspired me to think about publishing from my Honours research, and while my PhD quickly got in the way of that, this chapter is in fact a reworked early version of a paper drafted just after my Honours year. While my research interests have developed in very different directions since then, I have maintained a strong 'armchair' interest in the history of evolutionary thought and hope this contribution will excite others to revisit the works of the early evolutionary theorists. Much of my discussion concerns the nature of and the role of species in Lamarck's theory of evolution. Many readers are no doubt aware of Colin's own particular interest in species (see the discussion by Robert Attenborough, this volume, particularly with respect to the phylogenetic species concept) and while Colin may not necessarily agree with my interpretations of Lamarck on species, I am sure he would see it a most appropriate topic for this volume.

In popular and scientific mythology Darwin is reified as the founder of modern evolutionary theory and Lamarck lampooned as that 'odd chap' who believed in the inheritance of acquired characteristics. While not of concern here, the inheritance of acquired characteristics (what is now termed transgenerational epigenetic inheritance) would now seem to be a reality (see Morris, 2012 for an overview of recent developments in this area). The purpose of this chapter is not to bring Darwin 'down a peg', and in fact Darwin hardly gets a mention, but to entreat the reader to see Lamarck in an alternative light.

The role and influence of the French naturalist Jean-Baptiste Pierre Antoine de Monet, Chevalier de Lamarck (1744-1829) with regard to the development of evolutionary theory has been extensively researched over the past 50 years 
or so (Cannon, 1959; Gillispie, 1959; Lovejoy, 1959; Burkhardt, 1977, 1984; Hull, 1984; Lovtrup, 1987; Corsi, 1988) and is not pursued here. In this chapter I wish to review Lamarck's ideas on the nature of species, which directly relates to his evolutionary model, and then re-evaluate what I will argue are misinterpretations of two central aspects of this model: first, the view that Lamarck's theory was strictly vertical in nature and lacked a crucial horizontal component; secondly, that his evolutionary model is best viewed as a collection of multiple, independent lineages and is inconsistent with a theory of descent. Both of these themes are generally considered evidence of pivotal differences between Lamarck's and Darwinian, or modern, evolutionary theory. While I am not proposing that Darwin's theory of evolution be seen as resting on the foundations of Lamarck's theorising, I am asking that Lamarck at least be given a fair go in light of a close reading of his actual works.

\section{Zoological philosophy}

Coming from a background in botany Lamarck assumed the position of professor of invertebrates at the Museum National d'Histoire Naturelle in Paris in 1793 at 50 years of age. At the turn of the nineteenth century Lamarck made a seemingly abrupt ideological change with his conversion to evolutionism (Lamarck, 1800, 1802). Less than a decade later he became the first scholar (Lamarck, 1809) to publish a detailed theory of bio-evolution or transmutation. While neither of these terms were used by Lamarck, contemporary synonymous concepts such as 'changed', 'converted', 'mutation' and 'transformed' were used in their stead. Lamarck was also to a large extent responsible for integrating the threads of an emerging nineteenth century bio-evolutionary theory with the notion of progress.

Lamarck's most famous work, published in 1809 (the year of Darwin's birth), Zoological Philosophy, was not only a treatise on evolution but a system of biology treating three broad areas of study: (1) zoological classification and evolution; (2) the nature and causes of life; and (3) the nature and causes of intelligence, emotions and so forth. While the first part of this work dealt specifically with his evolutionary ideas, some sections on the origin of life in the second part of the work are important in understanding Lamarck's evolutionary model.

In his own lifetime Lamarck's views were essentially either ignored or actively disparaged (Cannon, 1959; Bowler, 1984, 2003; Burkhardt, 1984; Hull, 1984), although he received support in some quarters, the French naturalist Henri de Blainville for instance (see Appel, 1987). Perhaps one reason for Lamarck's dearth of support was related to his lack of compunction in seeing humanity as a creature of the evolutionary process. Cannon (1959) has also suggested that 
Georges Cuvier, a younger highly influential contemporary of Lamarck's, was the central cause of Lamarck's problems whilst living and dead. During his time at the Museum of Natural History Lamarck came into conflict with Cuvier over both geological gradualism and transmutation, both concepts to which Cuvier was totally antagonistic. The power and influence Cuvier wielded during these years (Coleman, 1964) did nothing for Lamarck's cause. Cannon (1959) has even suggested that nineteenth and twentieth century interpretations of Lamarck and his ideas stem from Cuvier's reinterpretations or misrepresentations. Indeed, in Cuvier's Biographical Memoir (Cuvier, 1831: 434) of Lamarck, he contrasted him to men of true genius:

[Those], with minds not less ardent, nor less adapted to seize new relations, have been less severe in scrutinizing the evidence; with real discoveries with which they have enriched science, they have mingled many fanciful conceptions; and, believing themselves able to outstrip both experience and calculation, they have laboriously constructed vast edifices on imaginary foundations, resembling the enchanted palaces of our old romances, which vanished into air on the destruction of the talisman to which they owed their birth.

Notwithstanding, Cuvier was one man and insufficient to the task of countering all materialist thought at the time (see Corsi, 1988). Burkhardt (1984) has outlined three additional reasons why Lamarck was so unsuccessful in his own time. In brief these are the materialist overtones of his work; his reputation for wild speculation; and the fact that he was 'unable to cultivate a circle of capable naturalists willing to champion his views' (Burkhardt, 1984: xxxiv). Moreover, less than three decades after his death, Lamarck was to present 'a serious public relations problem for Darwin and the Darwinians' (Hull, 1984: xlvi). Lamarck was perceived as Darwin's scientific precursor in a sense. Lyell even went as far as to describe Darwin's theory of evolution as a modification of Lamarck's views, much to the annoyance of Darwin (Hull, 1984). A perception of Darwinian evolution as Lamarckian evolution revisited (Lovtrup, 1987) would not have been an idea that would have sat well in the Darwin camp. Unfortunately, only Lamarck's mechanism for change survives as his legacy to the history of evolutionary thought. Furthermore, it is unlikely that Lamarck would recognise what was understood and presented as Lamarckism after his death (see Bowler, 1992).

\section{Lamarck on species}

Lamarck's particular understanding of species impacts on the two principal themes of this chapter and it is necessary to outline his ideas on this subject. 
Lamarck argued for the ability of species to change, and while not in itself ground breaking at the time, he presented his case by positing that species form a continuum:

I do not mean that existing animals form a very simple series, regularly graded throughout; but I do mean that they form a branching series, irregularly graded and free from discontinuity, or at least once free from it. For it is alleged that there is now occasional discontinuity, owing to some species being lost. (Lamarck, 1809: 37)

In his view species changed or transformed very gradually, that is by way of extremely small changes or micro-mutations over time. Because of this Lovtrup (1987) has argued that Lamarck was in fact the first micro-mutationist. Lamarck needed evolution to be gradual to fit with his understanding of deep geological time and views of environmental change.

As compared to the periods which we look upon as great in our ordinary calculations, an enormous time and wide variation in successive conditions must doubtless have been required to enable nature to bring the organization of animals to that degree of complexity and development in which we see it at its perfection. (Lamarck, 1809: 50)

Lamarck, like those after him who subscribed to the view of gradual species change, had a problem with species recognition. How does one separate a temporally and physically continuous entity into discrete units or species? Lamarck's solution was unique: species for him did not actually become extinct, although he noted the exception of recent cases of non-natural human induced extinctions. The fossil evidence in his time indicated many forms with no known contemporary representatives. Lamarck forwarded two explanatory arguments. The first, it was likely the living counterparts existed in the vast unexplored regions of the earth; the second and more important, species did not become extinct but they change over time by way of the accumulation of tiny mutations into new or different forms.

May it not be possible ... that the fossils [apparently representing extinct species] ... belonged to species still existing, but which have changed since that time and become converted into the similar species that we now actually find. (Lamarck, 1809: 45).

Species for Lamarck could encompass both broad levels of variation and temporal depth. In modern evolutionary terms Lamarck was describing the model of phyletic (anagenetic) evolution. This particular conceptualisation of what defined species allowed him to see them both change through time and retain their essential identity. 
There is, perhaps, an additional reason for Lamarck's subscription to this particular notion of species. It may have been a reaction to an interpretation of extinction events as the result of the non-viability of transmutated organisms. Such a view, if sustained, would constitute direct evidence against evolution. There is some evidence for this view when one considers opposition to transmutationism from Cuvier. Coleman (1964) and Bowler (1984) have noted that Cuvier, through his studies in comparative anatomy, had come to the conclusion that biological organisms were too complex to hold to the view transmutation could result in different viable organisms. For Cuvier species were fixed (implying species had a creationist and/or saltational origin). Lamarck saw transumtation occurring very gradually and there was certainly no place for useful monsters (the expected common result of large mutations as opposed to tiny unnoticed ones) in his scheme.

\section{Vertical and lateral evolution}

A number of scholars have either denied (Mayr, 1982, 1991) the idea of lateral, as opposed to vertical, evolutionary change in Lamarck's evolutionary model, or else seen this idea as having limited significance (Ruse, 1981, 1982; Bowler, 1984). It is Darwin who is generally credited with this ostensibly novel dichotomisation of evolutionary theory. For example, Mayr (1991: 17) argues that:

For Lamarck, evolution was a strictly vertical phenomenon, proceeding in a single dimension, that of time. Evolution for him was a movement from less perfect to more perfect, from the most primitive infusorians up to the mammals and man.

and

The problem of how these new species and incipient species came into being was clarified for Darwin by the Galapagos mockingbirds. These specimens showed that new species can originate by what we now call geographical (or allopatric) speciation...By this thought Darwin founded a branch of evolutionism which, for short, we might designate as horizontal evolutionism, in contrast with the strictly vertical evolutionism of Lamarck. (Mayr, 1991: 20)

Moreover, both Bowler $(1984,2003)$ and Ruse $(1981,1982)$ have tended to stress the idea that Lamarck was redeveloping the Medieval classificatory construct of a scale of being or scala natura, albeit a dynamic scale rather than a static one. Traditionally this scale concept was a hierarchical device that encompassed all 
life from the worms in the ground through to the angels themselves and even God. Each life form was ordered and ranked in such a manner as to create a continuous, unbroken but graduated chain of life (Hodgen, 1964).

Indeed, the concept of a scale of life is prominent in Lamarck's work. He outlined 14 classes of animals which were ranked or arranged from the single celled infusorian through to the most 'perfect' class mammals. Notwithstanding, Lamarck's understanding and use of the scala natura concept needs some explanation. For instance, what did Lamarck mean by the concept arrangement? Arrangement related to the order of his scale, in distinction to classification which referred specifically to the divisions within it. For example, Lamarck (1809: 56) defined arrangement as:

[A]n order in that list [referring to his classes] which represents as nearly as possible the actual order followed by nature in the production of animals; an order conspicuously indicated by the affinities which she has set between them.

However, this was not a simple continuous unilinear scale with evolution being represented by change over time (refer to the Lamarck, 1809: 37 quotation above) and Lamarck's views can be seen to be quite modern. Most evolutionary biologists today would accept some sort of loose macro-historical trend of less to more complex, mediated by the observation that the evolution of $B$ from $A$ is constrained by the nature of $A$ itself (see Mayr, 1982; Eldridge, 1985). Further, there are controversies and difficulties with current species concepts (e.g. Paterson, 1981; Eldridge, 1985; Tattersall, 1986), a topic to which Colin has also made important contributions (e.g. Groves, 2001). The point is that Lamarck was not simply reviving the scala natura in newer and more dynamic garb.

If not a simple unilineal scale what then was Lamarck's evolutionary scheme? In a summary of his own evolutionary views Lamarck notes:

Nature has produced all the species of animals in succession, beginning with the most imperfect or simplest, and ending her work with the most perfect, so as to create a gradually increasing complexity in their organization; these animals have spread at large throughout all the habitable regions of the globe, and every species has derived from its environment the habits that we find in it and the structural modifications which observation shows us. (Lamarck, 1809: 126)

Two themes are clearly presented here by Lamarck: the first is an implicit law of nature which causes the vertical progression from simple to complex organisation, based on the scala natura already spoken of; the second theme is the lateral secondary transformation of species due to the effects of environment, habit 
and so forth. Although this bi-directional scale of vertical continuity and lateral change was a major intellectual conceptualisation of the Renaissance theistic model of Adamitic origins and subsequent diffusion (see Hodgen, 1964), it is Lamarck who was responsible for appropriating it into an evolutionary model.

Lamarck's advocacy of lateral, or non-progressive, evolutionary change is further illustrated in his evolutionary diagram (see Figure 8.1). For instance there is an initial lateral branching from the worms into an annelids-cirrhipedes-molluscs evolutionary sequence on the one hand and an insects-arachnids-crustaceans sequence on the other. There is a similar major branching event at the reptiles. Further, there are a series of lateral bifurcations from an ancestral amphibian stock. That this is the manner in which Lamarck viewed evolutionary history, and not simply an interpretation seen through the lens of a modern understanding of evolution, is evident in his own comments concerning this diagram:

It is there shown that in my opinion the animal scale begins by at least two separate branches, and that as it proceeds it appears to terminate in several twigs in certain places. (Lamarck, 1809: 178)

The importance of this concept in his evolutionary model is further reinforced by other such specific references in his work:

As we continue to examine the probable origin of the various animals, we cannot doubt that the reptiles, by means of two distinct branches, caused by the environment, have given rise, on the one hand, to the formation of the birds and, on the other hand, to the amphibian mammals, which have in their turn given rise to all the other mammals. (Lamarck, 1809: 176; italics added)

The environment was the causal agent for Lamarck's other secondary, or lateral, component of his evolutionary model. It is evident that environmental influence played an important role in influencing evolutionary direction. Lamarck devoted a chapter (VII: 106-127) to his secondary evolutionary causal agent.

It is obvious then that as regards the character and situation of the substances which occupy the various parts of the earth's surface, there exits a variety of environmental factors which induces a corresponding variety in the shapes and structures of animals, independent of that special variety which necessarily results from the progress of the complexity of organisation in each animal. (Lamarck, 1809: 112)

Lamarck (1809: 127, italics added) went on in concluding his chapter on the role of environmental influence to state that:

[I]t is not the shape either of the body or its parts which give rise to the habits of animals and their mode of life; but that it is, on the contrary, 
the habits, mode of life and all the other influences of the environment which have in course of time built up the shape of the body and of the parts of animals. With new shapes, new faculties have been acquired, and little by little nature has succeeded in fashioning animals such as we actually see them.

It is clear that not only should Lamarck be given credit for the first comprehensive development of this vertical-lateral dichotomy within an evolutionary model, but that it was a fundamental component of his theory. Lamarck's answer to the riddle of specific diversity was a function of his lateral thinking.

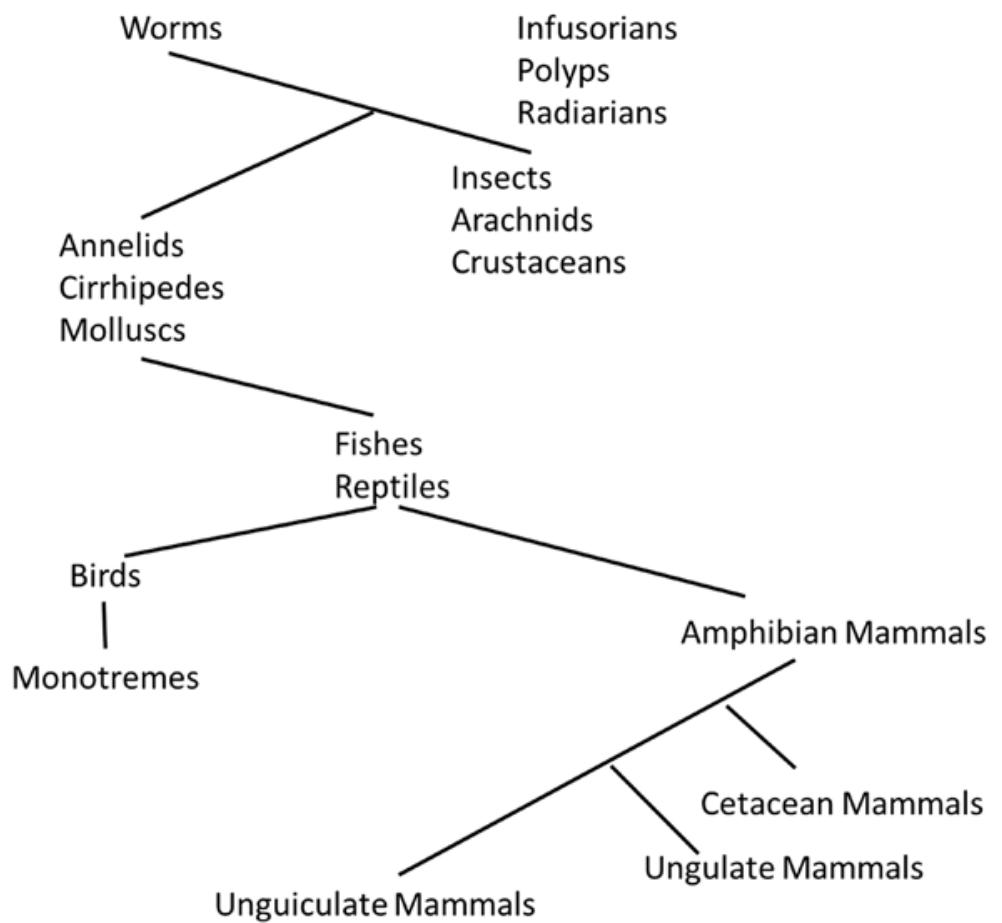

Figure 8.1: Diagram 'Showing the Origin of the Various Animals'.

Source: After Lamarck 1809: 179

\section{The multiple independent lineage view}

Giving precedence to Lamarck for first developing a vertical-lateral evolutionary model would not be accepted by Ruse $(1981,1982)$ and Bowler (1984), both of whom have argued that Lamarck's evolutionary model cannot be viewed 
as encompassing a theory of common descent. In fact Bowler claimed that the crucial difference between modern, or Darwinian, evolutionary theory and Lamarck's evolutionary views was that Lamarck '... did not suppose all forms alive to have evolved from a common ancestry' (Bowler, 1984: 80). For Lamarck complexity equated with temporal depth of lineage. Humans, for example, are the longest lived lineage which arose at the earliest period in time, relative to other lineages, from a separate spontaneous generation event (see Bowler, 1984 Fig. 10; 2003 Fig. 9). ${ }^{1}$ Lamarck is interpreted to be advocating multiple parallel lineages through time, each lineage having its roots in a separate and progressively later point of spontaneous generation (Bowler, 1984; Ruse, 1981, 1982). The most primitive species belong to the youngest lineages and in fact spontaneous generation is still occurring (Bowler, 1984; Ruse, 1981, 1982). However, I would argue that only the last point is partially correct.

Lamarck (1809: 247) devotes an entire chapter to the topic of spontaneous generation, which in summary is that:

[I]t appears to me certain that nature does herself carry out spontaneous or direct generations, that she has this power, and that she utilises it at the anterior extremity of each organic kingdom, where the most imperfect living bodies are found; and that it is exclusively through their medium that she has given existence to all the rest.

Note that in Lamarck's scheme there are only two organic kingdoms: the plants and animals. This is Lamarck's principal view regarding the origins and subsequent development or evolution of plant and animal life. However, Lamarck does pose the question that is apparently the cause of the (mis)interpretation of his main thesis representing multiple and independent evolutionary lineages through time:

[I]s it certain that she [nature] does not give rise to similar generations at any other point of these scales? (Lamarck 1809: 247)

When posing this question Lamarck (1809: 247) notes that he had hitherto held the view that:

[I]n order to give existence to all living bodies, it was enough for nature to have formed directly the simplest and most imperfect of animals and plants.

It is in this context that he (1809: 247) expands on his question:

\footnotetext{
1 Bowler (1984: fig. 10; 2003: fig. 9) does not provide an argument or evidence for this particular interpretation. Presumably his view is based on arguments by Ruse (e.g. 1982) who produces a very similar schematic (1982: fig. 1.4) to Bowler. As will be come apparent later in the chapter, Ruse (1982), has misinterpreted Lamarck on this issue.
} 
Why indeed should nature not give rise to direct generations at various points in the first half of the animal and plant scales, and even the origin of certain separate branches of these scales? Why should she not establish, in favourable circumstances, in these diverse rudimentary living bodies, certain physical systems of organisation, different from those observed at the points where the animal and vegetable scales appear to begin?

Having posed these questions they are then put aside as aspects worthy of further investigation, but not in any way central to his main thesis. He (1809: 248 , italics added) goes on to conclude this section thus:

Whether the kind of direct generations, here referred to, do or do not actually take place, as to which at present I have no settled opinion, it seems to me certain at all events that nature actually carries out such generations at the beginning of each kingdom of living bodies, and that she could never, except through this medium, have brought into existence the animals and plants which live on our earth.

Lamarck spent the majority of the first part of his book arguing that the dual agents of natural progress (vertical change) and environmental influence (lateral branching) acting on spontaneous generation events at the base of the plant and animal kingdoms are sufficient causes in and of themselves for producing the present variety and complexity of life. For Lamarck spontaneous generation is clearly important for the establishment of the animal and plant kingdoms, while the environment played a crucial role in subsequent branching events.

Not only has the direct formation of the simplest living bodies actually occurred [spontaneous generation], as I am about to show, but the following principles proves that such formations must still be constantly carried out and repeated where the conditions are favourable, in order that the existing state of things may continue. (Lamarck, 1809: 245)

The maintenance of the existing order Lamarck refers to is a reference to animals such as his infusorians (see Figure 8.1), which would become extinct, and thus disrupt the existing state of things, without continuous acts of spontaneous generation. In referring to the ephemeral and seasonal nature of these simplest of animals he goes on to state:

$[\mathrm{H}]$ ow fragile their existence, from what or in what way do they regenerate in the season when we again see them? Must we not think that these simple organisms, these rudiments of animality, so delicate and fragile, have been newly and directly fashioned by nature rather than have regenerated themselves? (Lamarck, 1809: 245) 
With the exception of the generation of the original plant and animal progenitors, these acts of continuous spontaneous generation were not seen by Lamarck as the starting points for new independent lineages. Except for fleetingly toying with the possibility of such a scenario, the idea of multiple separate and independent lineages was certainly not part of Lamarck's evolutionary model as substantively outlined in Zoological Philosophy.

Ruse (1981: 10) has argued that (and it is worth quoting him at length):

[O]ne must note that Lamarck's theory was in no way a theory of common descent, supposing that all organisms descended from one or a few common origins. We know that he thought simple forms of life are constantly being spontaneously generated through the action of heat, light, electricity and moisture on the inorganic world (Philosophie: 236248). Then organic development continues on essentially the same path it started on. Lamarck believed that lions and so on, if destroyed, would be replaced in the course of time (Philosophie: 187). There is therefore no reason to believe, for example, that today's mammals and today's fish have common ancestors- they are merely at different stages on the scale of being [see Figure 8.2].

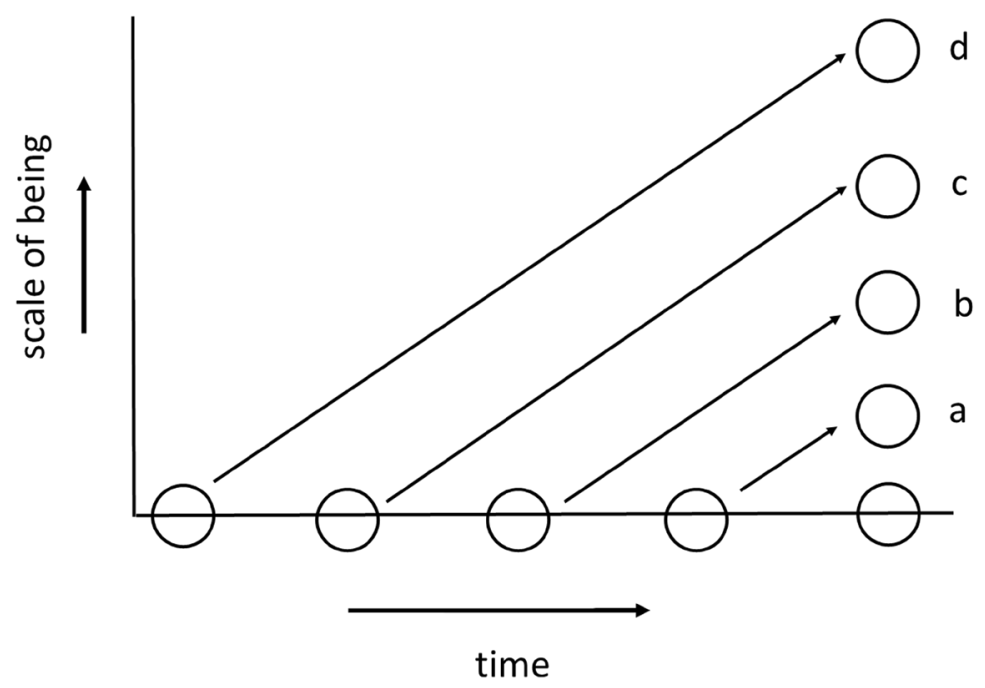

Figure 8.2: This is a modification of Ruse (1982: 8) following Bowler's (1984: Figure 10) interpretation of Lamarck's scheme. The circles along the $X$ axis represent the spontaneous generation events of the 'simplest' organisms, while the circles on the right hand side of the $\mathrm{Y}$ axis represent progressively more complex ( $d$ being the most complex) organisms that have unilinearly evolved from separate original spontaneous generation events. 
Whilst I have already addressed the majority of points raised in this statement, it is necessary to examine the reference to the lions and other animals, as this is clearly an important component of Ruse's argument for multiple, independent lineages. Lamarck has been taken out of context, and this is not a piece of evidence supporting the multiple independent lineage interpretation. In fact, this quote is taken from the introductory section of part two of Zoological Philosophy, dealing specifically with the physical causes, effects and manifestations of life, and not his evolutionary model per se.

After recognising the necessity for these acts of direct creation [spontaneous generation], we must enquire which are the living bodies that nature may produce spontaneously, and distinguish them from those which only derive their existence indirectly from her. Assuredly the lion, eagle, butterfly, oak, rose, do not derive their existence immediately from nature; they derive it as we know from individuals like themselves who transmit it to them by means of reproduction; and we may be sure that if the entire species of the lion or oak chanced to be destroyed in those parts of the earth where they are now distributed, it would be long before the combined powers of nature could restore them. (Lamarck, 1809: 186-187)

Lamarck is making two important points here, neither of which can be attributed to subscription to a model of multiple, independent lineages: (1) complex animals (e.g. lions and oaks) derive [descend] from other complex forms and are not the product of spontaneous generation; (2) enormous periods of time are involved in the complex process of evolution.

A final point before concluding concerns Bowler's $(1984,2003)$ view that the multiple, independent lineage model is the only one able to explain why, in Lamarck's world view, the scala natura is still visible. Lamarck provided two mechanisms to explain the continued existence of his scale. The first relates to his ideas on extinction: generally it does not happen. His understanding of the concept of species, examined previously, did not encompass the idea of extinction and this is why we still see life at all levels of organisational complexity. Secondly, and related to the first point, is the role of environmental influence again. In outlining his aims for the first part of Zoological Philosophy Lamarck (1809: 15, italics added) noted:

I shall [also] show the influence of environment and habit on the organs of animals, as being the factors which favour or arrest their development.

An example of this arrest in development can be seen in the way he dealt with an anti-evolutionary argument that used mummified Egyptian cats amongst other things. It was argued that as these cats, which were several thousand 
years old, were essentially identical to modern forms this proved that species did not change. Lamarck invoked the environmental argument to claim that the climate and environment in Egypt had not changed to any degree over the past several thousand years and thus one would not expect to see any change in Egyptian cats over this time. Progress, his vertical evolutionary component, would tend to cause all life to advance toward perfection. However, environmental influence, his lateral component, would serve to redirect and also arrest progressive advance. Lamarck's understanding of species and the role of the environment in his evolutionary model were sufficient in themselves to explain the apparent preservation of the arrangement of life as diagrammatically represented in Figure 8.1.

\section{Conclusions}

Ruse (1981) remarked that Lamarck was a very confusing writer and suggested this may have been because Lamarck was confused himself. True, Zoological Philosophy is written in a generally unclear and confusing style, but it is also apparent that he was struggling with a number of novel ideas and concepts. Even without an equivalent set of 'Darwin note books' it is clear that Zoological Philosophy has been through a number of drafts and alterations in theoretical orientation. Lamarck even noted in the preface to this work that this was a new, corrected and enlarged version of Recherches sur les corps vivants (Lamarck, 1802). Perhaps it is the clutter of these vestiges of changes in point of view that facilitated some of the misinterpretations of his work dealt with in this chapter.

Notwithstanding such concerns, Lamarck clearly and successfully grappled with the concepts of vertical and lateral evolutionary change. The view that he supported and promulgated a model of multiple, independent lineages all catalysed with their own independent spontaneous origin events is clearly not supported by a close reading of Lamarck's own words. Moreover, the development of the vertical and lateral dichotomy in Lamarck's model prefigured, at least, its appearance in Darwin's (1859) published model half a century later. What Lamarck gave us, whether anyone was listening or not, was a phylogentic model with two fundamental bifurcations, plant and animal, these in turn provided a multitude of environmentally induced branching events: a model of vertical and lateral evolutionary change.

Some 200 years after Lamarck published Zoological Philosophy, Colin Groves (Groves and Grubb, 2011; Gippoliti and Groves, 2012) was criticised for his own views on species (e.g. Zachos and Lovari, 2013). While I am sure Colin will be vindicated with time and, indeed, has made a stellar progress on this front (e.g. Gippoliti et al., 2013), I am not so sure about Lamarck. 
Taxonomic Tapestries

\section{References}

Appel TA. 1987. The Cuvier-Geoffroy debate: French biology in the decades before Darwin. New York: Oxford University Press.

Bowler PJ. 1984. Evolution: The history of an idea. Berkeley: University of California Press.

Bowler PJ. 1992. Lamarckism. In: Keller EV and Lloyd EA, editors. Keywords in evolutionary biology. Cambridge, MA: Harvard University Press. pp. 188-193.

Bowler PJ. 2003. Evolution: The history of an idea. Third edition. Berkeley: University of California Press.

Burkhardt RW Jr. 1977. The spirit of system: Lamarck and evolutionary biology. Cambridge: Cambridge University Press.

Burkhardt RW Jr. 1984. The zoological philosophy of J.B. Lamarck. In: Lamarck JB. Zoological philosophy: An exposition with regard to the natural history of animals. Translation of the 1809 edition by H Elliot. Chicago: The University of Chicago Press. p. xv-xxxix.

Cannon HG. 1959. Lamarck and modern genetics. Manchester: Manchester University Press.

Coleman W. 1964. Georges Cuvier, zoologist: A study in the history of evolution theory. Cambridge, MA: Harvard University Press.

Corsi P. 1988. The age of Lamarck: Evolutionary theories in France 1790-1830. Berkeley: University of California Press.

Cuvier G. 1831 [1984]. Biographical Memoir of M. De Lamarck. In: Lamarck JB. Zoological philosophy: An exposition with regard to the natural history of animals. Translation of the 1809 edition by H Elliot. Chicago: The University of Chicago Press. pp. 434-453.

Darwin C. 1859 [1985]. The origin of species by means of natural selection. Edited with an introduction by J.W. Burrow. Penguin Books.

Eldredge N. 1985. Unfinished synthesis: Biological hierarchies and modern evolutionary thought. New York: Oxford University Press.

Gillispie C. 1959. Lamarck and Darwin in the history of science. In: Glass B, Temkin O, and Straus W Jr., editors. Forerunners of Darwin: 1745-1859. Baltimore: Johns Hopkins University Press. pp. 265-291. 
Gippoliti S, Cotterill FPD, Groves CP. 2013. Mammal taxonomy without taxonomists: A reply to Zachos and Lovari. Hystrix 24(2):145-147.

Gippoliti S, Groves CP., 2012. "Taxonomic inflation" in the historical context of mammalogy and conservation. Hystrix 23(2):8-11.

Groves CP. 2001. Primate taxonomy. Washington, DC: Smithsonian Institution Press.

Groves CP, Grubb P. 2011. Ungulate taxonomy. Baltimore: Johns Hopkins University Press.

Hodgen MT. 1964. Early anthropology in the sixteenth and seventeenth centuries. Philadelphia: University of Pennsylvania Press.

Hull DL. 1984. Lamarck among the Anglos. In: Lamarck JB. Zoological philosophy: An exposition with regard to the natural history of animals. Translation of the 1809 edition by $\mathrm{H}$ Elliot. Chicago: The University of Chicago Press. p. xl-lxvi.

Lamarck JB. 1800. Introductory Lecture for 1800. In: Lamarck JB. Zoological philosophy: An exposition with regard to the natural history of animals. Translation of the 1809 edition by $\mathrm{H}$ Elliot. Chicago: The University of Chicago Press. pp. 407-433.

Lamarck JB. 1802. Recherches sur L'organisation Des Corps Vivants. Paris: Maillard.

Lamarck JB. 1809 [1984]. Zoological philosophy: An exposition with regard to the natural history of animals. Translated by $\mathrm{H}$ Elliot. Chicago: The University of Chicago Press.

Lovejoy AO. 1959. The argument for organic evolution before the origin of species, 1830-1858. In: Glass B, Temkin O, and Straus W Jr, editors. Forerunners of Darwin: 1745-1859. Baltimore: Johns Hopkins University Press. pp. 356-414.

Lovtrup S. 1987. Darwinism: The refutation of a myth. New York: Croom Helm in association with Methuen.

Mayr E. 1982. The growth of biological thought: Diversity, evolution, and inheritance. Cambridge, MA: Belknap Press.

Mayr E. 1991. One long argument: Charles Darwin and the genesis of modern evolutionary thought. Allen Lane: The Penguin Press.

Morris KV. 2012. Lamarck and the Missing Lnc. The Scientist 26(10):29-33. 
Taxonomic Tapestries

Paterson HEH. 1981. The continuing search for the unknown and unknowable: A critique of contemporary ideas on speciation. S Afr J Sci 77:113-119.

Ruse M. 1981. The Darwinian revolution: Science red in tooth and claw. Chicago: University of Chicago Press.

Ruse M. 1982. Darwinism defended: A guide to the evolution controversies. London: Addison-Wesley Publishing.

Tattersall I. 1986. Species recognition in human paleontology. J Hum Evol 15:165-175.

Zachos FE, Lovari S. 2013. Taxonomic inflation and the poverty of the Phylogenetic Species Concept - a reply to Gippoliti and Groves. Hystrix 24(2):142-144. 
This text is taken from Taxonomic Tapestries: The Threads of Evolutionary, Behavioural and Conservation Research, edited by Alison M Behie and Marc F Oxenham, published 2015 by ANU Press, The Australian National University, Canberra, Australia. 